DR LASSE RAATINIEMI (Orcid ID : 0000-0001-5537-9749)

DR PIRITTA ANNIINA SETÄLÄ (Orcid ID : 0000-0003-0850-8485)

DR JOUNI NURMI (Orcid ID : 0000-0002-1920-4869)

Article type : Clinical investigation

\title{
Shock index as a predictor for short term mortality in helicopter emergency medical services: a registry study
}

Johannes Björkman,1,2* Lasse Raatiniemi,3 Piritta Setälä,4 Jouni Nurmi1,5

1. FinnHEMS Research and Development Unit, Finland

2. University of Helsinki, Helsinki, Finland

3. Centre for Emergency Medical Services, Oulu University Hospital, Oulu, Finland

4. Emergency Medical Services, Tampere University Hospital, Tampere, Finland

5. Emergency Medicine and Services, Helsinki University Hospital and Emergency Medicine, University of Helsinki, Finland

* Corresponding author:

Johannes Björkman, MD

WTC Helsinki Airport

Lentäjäntie 3

01530 Vantaa, Finland

Tel: +35844 43298724

This article has been accepted for publication and undergone full peer review but has not been through the copyediting, typesetting, pagination and proofreading process, which may lead to differences between this version and the Version of Record. Please cite this article as doi:

$\underline{10.1111 / \text { AAS. } 13765}$

This article is protected by copyright. All rights reserved 
Fax: n/a

Email: johannes.bjorkman@finnhems.com

Short title: Prehospital shock index

2914 words

Keywords: shock, mortality, emergency medical services, air ambulances

This article is protected by copyright. All rights reserved 


\section{ABSTRACT}

\section{Background}

The value of shock-index has been demonstrated in hospital triage, but few studies have evaluated its prehospital use.

The aim of our study was to evaluate the association between shock-index in prehospital critical care and short-term mortality.

\section{Methods}

We analyzed data from the national helicopter emergency medical services database and the Population Register Centre. The shock-index was calculated from the patients' first measured parameters. The primary outcome measure was 1- and 30-day mortality.

Results

A total of 22433 patients were included. The 1-day mortality was 7.5\% and 30-day mortality was $16 \%$. The median shock-index was $0.68(0.55 / 0.84)$ for survivors and $0.67(0.49 / 0.93)$ for non-survivors $(P=.316)$ at 30 -days.

Association between shock-index and mortality followed a U-shaped curve in trauma (shock-index <0.5: odds ratio 2.5 [95\% confidence interval 1.8-3.4], shock-index $>1.3$ : odds ratio 4.4 [2.7-7.2] at 30 days). Patients with neurological emergencies with a low shock-index had an increased risk of mortality (shock-index $<0.5$ : odds ratio 1.8 $[1.5-2.3])$ whereas patients treated after successful resuscitation from out-of-hospital cardiac arrest, a higher shockindex was associated with higher mortality (shock-index $>1.3$ : odds ratio 3.5 [2.3-5.4). The association was similar for all ages, but older patients had higher mortality in each shock-index category.

\section{Conclusion}

The shock-index is associated with short time mortality in most critical patient categories in the prehospital setting. However, the marked overlap of shock-index in survivors and non-survivors in all patient categories limits its predictive value.

\section{Editorial Comment}

Shock in the prehospital resuscitation situation is not one specific condition, and it can be life-threatening. In this study, an initial shock-index assessment from the prehospital site showed some relation to short-term survival, but this was limited in this large group assessment. The first vital signs do not seem to be strongly predictive of how patients will respond to resuscitation and hospitalization. 


\section{INTRODUCTION}

The use for medical helicopters has evolved significantly during the last decades. However, Helicopter Emergency Medical Services (HEMS) are an expensive and often limited resource that should be used rationally. HEMS aims to offer their services to the most critically ill to provide more sustainable outcomes. ${ }^{1}$ The treatment of critically ill prehospital patients is a clinical team-work effort with limited laboratory and imaginary options.

The shock index (SI), which is acquired by dividing the heart rate by the systolic blood pressure, has been used as a tool to discern patients in serious cardiovascular distress. ${ }^{2}$ Currently, the SI is recommended by the European Trauma Guidelines for the treatment of exsanguinating trauma, and it has been shown to be useful as a tool when treating cardiovascular emergencies. $^{3-5}$ A Danish study showed the SI's applicability in the triage of a heterogenous patient population presenting to the emergency department. ${ }^{6}$ However, in certain conditions, such as ruptured ectopic pregnancy, upper gastrointestinal bleed or pulmonary embolism, SI has been of less value, and its use in the pediatric population is not established..$^{7-9}$ Furthermore, cardiac arrythmias and cardiovascular medications can affect the index. ${ }^{10}$ The patient's age also affects the SI's prognostic value: multiplying the age with SI yields the age-SI, which has been shown to be valuable in geriatric patients. ${ }^{7}$

In the prehospital setting, the patient population is unselected, and the resources regarding the patients' medical history may be limited. Previous prehospital studies on SI have found it beneficial in trauma management to guide the administration of blood products and prepare the receiving hospital. ${ }^{11-14}$ Moreover, among septic patients, a high prehospital SI has been shown to be associated with an increased risk of mortality. ${ }^{15}$ For prehospital patients SI could assist in the secondary HEMS dispatch by the EMS crew attending the call. SI could also be used by the dispatched HEMS unit to allocate resources upon primary report from the first attending EMS unit, as a surrogate for the degree of physiological impairment in data collection for HEMS management and for scientific purposes.

The aim of our study was to investigate the ability of SI to predict short-term mortality in different patient- and age categories encountered by HEMS. We hypothesized that a higher SI is associated with increased one-day mortality in all patient categories.

This article is protected by copyright. All rights reserved 


\section{METHODS}

\section{Study design}

Our study was a retrospective cohort study using data from the national HEMS database and the Population Registry Centre. All HEMS dispatches between January 1, 2012 and September 8, 2019 were included in the study. The chosen dates represent the establishment of the database and the latest practical data collection point. All entries to FHDB were eligible. We were granted study permission from all participant hospital districts (Oulu University Hospital 200/2019 2.7.2019, Helsinki University Hospital HUS/280/2019 9.7.2019, Turku University Hospital J30/19

4.8.2019, Hospital District of Lapland 32/2019 22.8.2019, Kuopio University Hospital RPL 102/2019 22.8.2019 and Tampere University Hospital RTL-R19580 2.9.2019). The protocol was reviewed and approved by the Ethical Board of Helsinki University Hospital (HUS/3115/2019 §194). Permission was requested and granted by the Population Registry Centre (VRK/5613/2019-3 1.11.2019) to acquire the patients' mortality data. The Strengthening the Reporting of Observational Studies in Epidemiology (STROBE) statement is followed in reporting the study. ${ }^{16}$

\section{Setting}

We included data from all six HEMS units operating in Finland. The Finnish HEMS system and its characteristics have recently been described in detail elsewhere. ${ }^{1}$ In brief, it consists of five physician-staffed units and one paramedic-staffed unit, based at the University Hospitals and Lapland, respectively. The units use either helicopters or rapid response cars in response to dispatches, depending on distance and aviation factors. The units are primarily dispatched by the emergency response centers according to national dispatch criteria with slight regional variations. HEMS are usually dispatched simultaneously with the responding EMS, differing somewhat from other HEMS systems. Typical missions include OHCA, major trauma and unconsciousness with an unknown origin. All bases use the FinnHEMS database (FHDB) to report all calls. The FHDB incorporates alarm details in excess of the standing recommendations. ${ }^{17}$

The Population Register Centre collects data regarding citizens residing in Finland, including age, sex, place of residence, marital status and dates of birth and death. Individual patients can be identified and tracked based on a personal identification number given at birth or received on gaining access to healthcare and social welfare services after immigration.

\section{Participants and outcome measures}

Inclusion criteria for our study were age 18 years or over, measured and registered heart rate and systolic blood pressure upon HEMS contact and mortality data available from the Patient Register Centre. We excluded patients with unknown age, missing heart rate or blood pressure, unmeasurable hemodynamic parameters (e.g. ongoing cardiac resuscitation) or missing data from the Patient Register Centre. The first heart rate and systolic blood pressure measured at the initiation of HEMS care were used as the SI values. 
Mortality data were extracted from the Finnish Population Register Centre on November 10, 2019. The primary outcome measure was survival at 1- and 30 days after the prehospital event. Secondary outcomes were mortalities in different subgroups following logistic regression analysis. The presenting medical problem was categorized in the FHDB following the international consensus statement of data collection from physician-staffed prehospital services. ${ }^{17}$ For this study, the categories were combined into five groups based on the number of patients in different categories as follows: trauma, OHCA, neurological (including stroke), intoxication, and other problems. The group labelled other included patients with respiratory distress, chest pain, infections, obstetrical emergencies. SI was categorized into five groups: $<0.5,0.5-0.7$ (normal range, selected as the reference category), $>0.7-0.9,>0.9-1.3$ and $>1.3$. Patients were categorized by age into three age groups: 18-64 years (reference category), 65-79 years and over 80 years. Glasgow Coma Scale (GCS) was categorized into four groups; 15 (reference category), 14-9, 4-8 and 3 . Patients were followed until 30 days, death, emigration or November 10, 2019, whichever came first.

\section{Statistical methods}

We present the quantitative variables as means and medians and their standard deviation $( \pm \mathrm{SD})$ or interquartile range $\left(1^{\text {st }}\right.$ quartile/ $/ 3^{\text {rd }}$ quartile), respectively, depending on the distribution. Categorial variables are presented as $\mathrm{n}(\%)$. Mortality values are expressed as percentages with their respective $95 \%$ confidence interval (CI). We used a $P$ value of $<.05$ as evidence against the null hypothesis. Comparisons were calculated with the Chi-square, the Mann-Whitney $\mathrm{U}$ test and the two-sample t-test where applicable. A multivariable logistic regression was used to study the effect of gender, age-, shock index- and GCS-category for death at 1-day and 30-days for the different medical problems. The Hoshmer-Lemeshow test was used with a $P<.05$ indicating a poor fit. We used SPSS 25 (IBM SPSS Statistics 25, IBM Corporation, Armonk, NY, USA) and Prism 8 (GraphPad Prism 8, GraphPad Software, San Diego, CA, USA) to calculate the data.

This article is protected by copyright. All rights reserved 


\section{RESULTS}

Out of the total of 36715 patients encountered during the study period, 22433 (61\%) were eligible for the study and used for analyses (Figure 1). The patient characteristics and comparisons are shown in Table 1. In patients presenting with trauma, the cause was blunt force trauma in 5290 (85.6\%) cases and penetrating trauma in 815 (13.2\%) cases, while the remaining 73 (1.2\%) had another trauma modality. The median time from alarm to HEMS contact was 21 $(14 / 33)$ minutes.

The all-cause 1-day mortality was $7.5 \%$ and 30 -day mortality was $16 \%$. For excluded patients with hemodynamic parameters registered as unmeasurable or not measured $(\mathrm{n}=8892)$ the 30 -day mortality was $81 \%$. The median SI was $0.68(0.55 / 0.84)$ for survivors and $0.67(0.49 / 0.93)$ for non-survivors $(P=.316)$. Survivors were significantly younger than non-survivors (median 55.8 [36.4/70.0] vs $72.6[62.8 / 81.5], P<.001$ ). Mortality by SI for different medical problems and age categories is shown in Figure 2. The association of SI and mortality showed a U-shaped tendency in patients presenting with trauma and neurological problems. In the other categories a more linear association could be seen. Inconsistency in the development of the mortality trend in patients $\geq 80$ years between SI's $0.9-1.3$ and $>1.3$ was observed; however, it was within CI limits and thus no clear correlation could be made. Figure 3 shows the results from the logistic regression analysis. The results at 30-days showed a similar trend and are presented in Supplement 1. Older patients were clearly at an increased risk for death, while female gender was only a risk in the OHCA category. For all categories except for patients with an intoxication, a lower GCS was associated with an increased mortality.

\section{DISCUSSION}

Our main finding is that an elevated SI in prehospital critical care is associated with an increased risk of short-term mortality. The association is different depending on the presenting medical problem. For patients with a neurological problem or trauma, a low SI seems to be associated with a marked risk of death.

\section{Strengths and limitations}

Our study's strengths include the data's extent and completeness. The FHDB comprises national data from all the HEMS operations in Finland, as FinnHEMS is the sole operator. In addition, our study combined the nationwide population registry data with data from the HEMS operations. The data in both registries can be considered valid. The study population was limited to prehospital patients presenting with a critical illness who were encountered by HEMS. As such, the results cannot be generalized to all prehospital patients. In addition, these patients received prehospital intensive care before hospital admission, and comparison to patients in the emergency room or the intensive care unit is difficult. The results can be generalized mainly to a mixed urban/suburban/rural HEMS population, in which HEMS are part of the primary response.

This article is protected by copyright. All rights reserved 
The hemodynamic parameters obviously affect the treatment received — both pre-hospital and in hospital. Factors such as the need for vasopressors, fluid resuscitation and underlying chronic conditions and medications were not taken into account when regarding mortality in this study. Since physiological deterioration is a dynamic process, this may have a significant effect on the results of the study.

Missing data from one-fifth of the encountered patients confound the results. Patients with missing data had a 30-day mortality rate of $81 \%$. This remarkably high mortality represents patients with ongoing cardiopulmonary resuscitation upon HEMS contact or situations that were so dire that measurements were not - or could not - be performed (i.e., ongoing extrication).

We also found a number of factors with a statistic significance but with little clinical relevance (i.e. patients who died had a lower median systolic blood pressure, though still normotensive and that the median SI in survivors and nonsurvivors did not differ). It is important to keep the clinical context in mind when performing and interpreting results from research.

\section{Interpretation}

Overall, only a few publications have examined the relationship between prehospital SI and mortality. To the best of our knowledge, this is the first study reporting the association of SI in the critically ill prehospital patients. The findings are in line with previous preliminary observations in more focused patient populations. Studies have shown that an elevated SI can be used to guide the resources (e.g. triage or the use of massive transfusion protocols) of the receiving hospital. ${ }^{18}$ Furthermore, Jouffroy et al observed higher mortality in septic patients with an elevated prehospital SI. ${ }^{19}$ For patients with a ruptured aortic aneurysm, Noëlle et al found that an elevated prehospital SI was associated with an increased mortality rate and emergency surgery. ${ }^{20}$

In our study, trauma patients' mortality was elevated in the extremes of SI. The same observation of bimodal distribution has been made in a retrospective study by Odom et al involving of more than 10,000 patients suffering from trauma. ${ }^{21}$ Regrettably, our data sources did not allow separation of isolated traumatic brain injury (TBI) from other causes of trauma during the study period, which would allow for a more profound comparison of our studies. However, neurological patients with a low SI had a similar increase, suggesting that increased mortality is most likely a consequence of an expanding intracranial catastrophe (TBI or spontaneous cerebral hemorrhage) and reflects the Cushing's triad (hypertension, bradycardia and Cheyne-Stokes breathing). ${ }^{22}$ The increased risk for death with a decreased GCS in our study also supports this theory. 
Patients who suffer from OHCA represent one of the largest categories encountered by Finnish HEMS. ${ }^{1}$ After a return of spontaneous circulation (ROSC), post-resuscitation syndrome, with the associated cardiovascular distress, can ensue. Myocardial dysfunction can be a consequence of stunning caused by ischemia and reperfusion and thus a reversible phenomenon. ${ }^{23}$ Earlier studies have demonstrated an association between early hypotension and mortality. ${ }^{24}$ However, another component of SI, the heart rate, was not addressed in those studies. It must be kept in mind that patients had achieved ROSC and had been resuscitated as per European Resuscitation Council guidelines and presumably received epinephrine during resuscitation. ${ }^{25}$ Epinephrine increases both heart rate and blood pressure and could confound the result in the extremely early phase.

In our study, in patients who did not suffer from any of the major medical problem categories we observed a gradual increase in mortality in all age groups with an increase in SI. This category included patients suffering from cardiovascular and respiratory emergencies and infections, mimicking results from previous studies in hospitalized patients. ${ }^{15,26,27}$ Also, a decreased state of consciousness was associated with an increased mortality rate, clearly reflecting the clinical situation — if the respiratory distress affects the brain metabolism, death might ensue without interventions.

Due to the marked overlap of SI in survivors and non-survivors in all of our patient categories, we hypothesized that the predictive value of SI is limited and should not be used solely in individual patients. Potentially, SI could be more helpful in describing patient characteristics at the system level, or it could be used as a component used to report patient findings. Furthermore, the trend of SI as a marker of response for treatment given may be more useful than a single value. ${ }^{28}$ However, this was not addressed by the current study design.

One-day and 30-day mortality rates are simple and robust outcome measures, but future studies could evaluate if abnormal SI — or changes in SI — predicts the need and use of advanced prehospital interventions. Observing changes in SI would also allow the inclusion of patients encountered without recordable or recorded hemodynamic parameters. Moreover, combining the results of clinical judgement and point-of-care analyses, such as ultrasound or blood gas analysis, with SI could improve SI's predictive value.

To conclude, SI is associated with short-term mortality in most patient categories encountered by HEMS. However, due to significant overlapping SI in survivors and non-survivors, the value of SI in identifying the most critically ill patients or guiding treatment may be limited. The association between SI and short-term mortality is varies in different patient categories, which further decreases the value of SI as general tool to identify increased risk of death.

This article is protected by copyright. All rights reserved 


\section{ACKNOWLEDGEMENTS}

Funding information

This study was funded by Helsinki University Hospital (state funding, VTR TYH2019243) and the Research and Development Unit of FinnHEMS.

Conflict of interest

The authors have no conflicting interests to disclose.

This article is protected by copyright. All rights reserved 


\section{REFERENCES}

1. Saviluoto A, Björkman J, Olkinuora A, Virkkunen I, Kirves H, Setälä P, Pulkkinen I, Laukkanen-Nevala P, Raatiniemi L, Jäntti H, Iirola T, Nurmi J. The first seven years of nationally organized helicopter emergency medical services in Finland - the data from quality registry.Scand J Trauma Resusc Emerg Medicine 2020; 28: 46.

2. Allgöwer M, Burri C. „Schockindex”.Dmw - Deutsche Medizinische Wochenschrift 1967; 92: 1947-50.

3. Yu T, Tian C, Song J, He D, Sun Z, Sun Z. Age Shock Index is Superior to Shock Index and Modified Shock Index for Predicting Long-Term Prognosis in Acute Myocardial Infarction.Shock Augusta Ga 2017; 48: 545-50.

4. Spahn DR, Bouillon B, Cerny V, Duranteau J, Filipescu D, Hunt BJ, Komadina R, Maegele M, Nardi G, Riddez L, Samama C-M, Vincent J-L, Rossaint R. The European guideline on management of major bleeding and coagulopathy following trauma: fifth edition.Critical Care Lond Engl 2019; 23: 98.

5. Kim SY, Hong KJ, Shin SD, Ro YS, Ahn KO, Kim YJ, Lee EJ. Validation of the Shock Index, Modified Shock Index, and Age Shock Index for Predicting Mortality of Geriatric Trauma Patients in Emergency Departments.J Korean Med Sci 2016; 31: 2026-32.

6. Holler JG, Henriksen DP, Mikkelsen S, Rasmussen LM, Pedersen C, Lassen AT. Shock in the emergency department; a 12 year population based cohort study.Scand J Trauma Resusc Emerg Medicine 2016; 24: 87.

7. Koch E, Lovett S, Nghiem T, Riggs R, Rech MA. <p $>$ Shock index in the emergency department: utility and limitations $</$ p $>$. Open Access Emerg Medicine 2019; Volume 11: 179-99.

This article is protected by copyright. All rights reserved 
8. Nordin A, Shi J, Wheeler K, Xiang H, Kenney B. Age-adjusted shock index: From injury to arrival.J Pediatr Surg 2019; 54: 984-8.

9. Saffouri E, Blackwell C, Laursen SB, Laine L, Dalton HR, Ngu J, Shultz M, Norton R, Stanley AJ. The Shock Index is not accurate at predicting outcomes in patients with upper gastrointestinal bleeding.Aliment Pharm Therap 2019; 51: 253-60.

10. Kristensen AKB, Holler JG, Hallas J, Lassen A, Shapiro NI. Is Shock Index a Valid Predictor of Mortality in Emergency Department Patients With Hypertension, Diabetes, High Age, or Receipt of $\beta$ - or Calcium Channel Blockers?Ann Emerg Med 2016; 67: 106-113.e6.

11. Kim MJ, Park JY, Kim MK, Lee JG. Usefulness of Shock Index to Predict Outcomes of Trauma Patient: A Retrospective Cohort Study.J Trauma Inj 2019; 32: 17-25.

12. Shand S, Curtis K, Dinh M, Burns B. Prehospital Blood Transfusion in New South Wales, Australia: A Retrospective Cohort Study.Prehosp Emerg Care 2020; 1-8.

13. Pottecher J, Ageron F-X, Fauché C, Chemla D, Noll E, Duranteau J, Chapiteau L, Payen J-F, Bouzat P. Prehospital shock index and pulse pressure/heart rate ratio to predict massive transfusion after severe trauma: Retrospective analysis of a large regional trauma database.J Trauma Acute Care Surg 2016; 81: 713-22.

14. Vandromme MJ, Griffin RL, Kerby JD, McGwin G, Rue LW, Weinberg JA. Identifying risk for massive transfusion in the relatively normotensive patient: utility of the prehospital shock index.J Trauma 2011; 70: 384-8; discussion 388-90.

15. Jouffroy R, Tourtier JP, Gueye P, Bloch-Laine E, Bounes V, Debaty G, Boularan J, Carli P, Vivien B. Prehospital shock index to assess 28-day mortality for septic shock.Am J Emerg Medicine 2019. doi: 10.1016/j.ajem.2019.11.004

16. Elm E von, Altman DG, Egger M, Pocock SJ, Gøtzsche PC, Vandenbroucke JP, Initiative S. The Strengthening the Reporting of Observational Studies in Epidemiology (STROBE) Statement: Guidelines for reporting observational studies.Int J Surg 2014; 12: 1495-9.

This article is protected by copyright. All rights reserved 
17. Krüger AJ, Lockey D, Kurola J, Bartolomeo SD, Castrén M, Mikkelsen S, Lossius HM. A consensus-based template for documenting and reporting in physician-staffed pre-hospital services.Scand J Trauma Resusc Emerg Medicine 2011; 19: 71.

18. Jehan F, Con J, McIntyre M, Khan M, Azim A, Prabhakaran K, Latifi R. Pre-hospital shock index correlates with transfusion, resource utilization and mortality; The role of patient first vitals.Am J Surg 2019; 218: 1169-74.

19. Jouffroy R, Tourtier JP, Gueye P, Bloch-Laine E, Bounes V, Debaty G, Boularan J, Carli P, Vivien B. Prehospital shock index to assess 28-day mortality for septic shock.Am J Emerg Medicine 2019. doi: 10.1016/j.ajem.2019.11.004

20. Dirks NPM, Mestrom M, Lugt M van der, Osch F van, Peters NALR, Elshof J-WM, Barten DG. Utility of Shock Index for Suspected Rupture of Abdominal Aortic Aneurysms.Prehosp Emerg Care 2020; 1-8.

21. Odom SR, Howell MD, Gupta A, Silva G, Cook CH, Talmor D. Extremes of shock index predicts death in trauma patients.J Emergencies Trauma Shock 2016; 9: 103-6.

22. Cushiing H. The blood-pressure reaction of acute cerebral compression, illustrated by cases of intracranial hemorrhage. Am J Medical Sci 1903; 125: 1017-43.

23. Neumar RW, Nolan JP, Adrie C, Aibiki M, Berg RA, Böttiger BW, Callaway C, Clark RSB, Geocadin RG, Jauch EC, Kern KB, Laurent I, Longstreth WT, Merchant RM, Morley P, Morrison LJ, Nadkarni V, Peberdy MA, Rivers EP, Rodriguez-Nunez A, Sellke FW, Spaulding C, Sunde K, Hoek TV. Post-Cardiac Arrest Syndrome: Epidemiology, Pathophysiology, Treatment, and Prognostication A Consensus Statement From the International Liaison Committee on Resuscitation (American Heart Association, Australian and New Zealand Council on Resuscitation, European Resuscitation Council, Heart and Stroke Foundation of Canada, InterAmerican Heart Foundation, Resuscitation Council of Asia, and the Resuscitation Council of Southern Africa); the American Heart Association Emergency Cardiovascular Care Committee; the Council on Cardiovascular Surgery and Anesthesia; the Council on Cardiopulmonary,

This article is protected by copyright. All rights reserved 
Perioperative, and Critical Care; the Council on Clinical Cardiology; and the Stroke Council.Circulation 2008; 118: 2452-83.

24. Bhate TD, McDonald B, Sekhon MS, Griesdale DEG. Association between blood pressure and outcomes in patients after cardiac arrest: A systematic review.Resuscitation 2015; 97: 1-6.

25. Soar J, Nolan JP, Böttiger BW, Perkins GD, Lott C, Carli P, Pellis T, Sandroni C, Skrifvars MB, Smith GB, Sunde K, Deakin CD, Collaborators on behalf of the A advanced life support section, Koster RW, Monsieurs KG, Nikolaou NI. European Resuscitation Council Guidelines for Resuscitation 2015: Section 3. Adult advanced life support.Resuscitation 2015; 95: 100-47.

26. Yu T, Tian C, Song J, He D, Sun Z, Sun Z. Derivation and Validation of Shock Index as a parameter for Predicting Long-term Prognosis in Patients with Acute Coronary Syndrome.Sci Rep-uk 2017; 7: 11929.

27. Sahu N, Yee S, Das M, Trinh S, Amoruso R, Connolly M, Rama A, Zuberi J, N S, S Y, M D, S T, R A, M C, A R, J Z. Shock Index as a Marker for Mortality Rates in Those Admitted to the Medical Intensive Care Unit from the Emergency Department.Cureus 2020; 12. doi:

10.7759/cureus.7903

28. Shand S, Curtis K, Dinh M, Burns B. Prehospital Blood Transfusion in New South Wales, Australia: A Retrospective Cohort Study.Prehosp Emerg Care 2020; 1-8.

This article is protected by copyright. All rights reserved 
Table 1. Characteristics of patients at 1-day and 30-day follow-up. Data are presented as n (\%) mean ( $(\mathrm{SD})$ or median ( $1^{\text {st }}$ quartile/3 $3^{\text {rd }}$ quartile).

Figure 1. Flowchart of the patient selection.

Note: FHDB, FinnHEMS database, BP, blood pressure.

Figure 2. Mortality (\%), with their corresponding 95\% CI, in different age categories per SI- and age-groups and medical problem for 1- and 30-days.

Figure 3 Odds ratio $(95 \% \mathrm{CI})$ for one-day mortality for different medical problems for HEMS dispatch. Note the different scales on the $\mathrm{x}$-axes. SI $=$ Shock Index, GCS = Glasgow Coma Scale, OHCA = Out-of-hospital cardiac arrest, $\mathrm{OR}=$ Odds ratio, $\mathrm{CI}=$ Confidence interval

Supplement 1. Logistic regression analysis of factors associated with SI and mortality at 1- and 30-days. Numbers are presented as $n(\%)$ or Odds Ratio (95\% confidence interval). SI $=$ Shock Index, GCS = Glasgow Coma Scale, OHCA $=$ Out-of-Hospital Cardiac Arrest

This article is protected by copyright. All rights reserved 
Table 1. Characteristics of patients at 1-day and 30-day follow-up. Data are presented as $n(\%)$ mean $\left( \pm\right.$ SD) or median $\left(1^{\text {st }}\right.$ quartile $/ 3^{\text {rd }}$ quartile $)$.

\begin{tabular}{|c|c|c|c|c|c|c|c|}
\hline & & \multicolumn{3}{|c|}{ 1-day } & \multicolumn{3}{|c|}{ 30-day } \\
\hline & All & Survivor & Non-survivor & $P$ value & Survivor & Non-survivor & $P$ value \\
\hline & 22433 & $20743(92.5)$ & $1690(7.5)$ & & $18847(84.0)$ & $3586(16.0)$ & \\
\hline Age, years & $59.4(40.0 / 72.8)$ & $57.9(38.4$ / 71.6) & $72.7(62.5$ / 81.3) & $<0.001^{!}$ & $55.8(36.4 / 70.0)$ & $72.6(62.8 / 81.5)$ & $<0.001^{!}$ \\
\hline $18-64$ & $13447(59.9)$ & 12915 (96.2) & $508(3.8)$ & \multirow{3}{*}{$<0.001^{*}$} & $12354(92.0)$ & $1069(8.0)$ & \multirow{3}{*}{$<0.001^{*}$} \\
\hline $65-79$ & $5996(26.7)$ & $5294(88.5)$ & $690(11.5)$ & & $4521(75.6)$ & $1463(24.4)$ & \\
\hline$\geq 80$ & $2990(13.3)$ & $2499(83.6)$ & $489(16.4)$ & & $1937 .(64.8)$ & $1051(35.2)$ & \\
\hline Sex, male & $14023(62.5)$ & $13014(62.8)$ & $988(58.6)$ & $<0.001 "$ & $11883(63.2)$ & $2119(59.1)$ & $<0.001$ \\
\hline Heart rate, $1 / \mathrm{min}$ & $93( \pm 27)$ & $93( \pm 26)$ & $90( \pm 30)$ & $0.001^{\#}$ & $93( \pm 26)$ & $93( \pm 29)$ & $0.411^{\#}$ \\
\hline Systolic blood pressure, $\mathrm{mmHg}$ & $133(112 / 155)$ & $133(113 / 155)$ & $128(92 / 165)$ & $0.029^{\#}$ & $132(114 / 154)$ & $134(102 / 168)$ & $0.05^{\#}$ \\
\hline Glasgow Coma Scale & $13(6 / 15)$ & $14(7 / 15)$ & $3(3 / 7)$ & $<0.001 *$ & $14(8 / 15)$ & $4(3 / 9)$ & $<0.001^{*}$ \\
\hline Shock Index & $0.68(0.54 / 0.85)$ & $0.68(0.54 / 0.84)$ & $0.68(0.47 / 1.00)$ & $0.509^{!}$ & $0.68(0.55 / 0.84)$ & $0.67(0.49 / 0.93)$ & $0.316^{!}$ \\
\hline \multicolumn{8}{|l|}{ Medical Problem } \\
\hline Trauma & $6180(27.5)$ & $5892(95.5)$ & $275(4.5)$ & \multirow{8}{*}{$<0.001^{*}$} & $5635(91.4)$ & $532(8.6)$ & \multirow{8}{*}{$<0.001^{*}$} \\
\hline Blunt & $5290(85.6)$ & $5041(95.5)$ & $237(4.5)$ & & $4808(91.1)$ & $470(8.9)$ & \\
\hline Penetrating & 815 (13.2) & $782(96.0)$ & $33(4.0)$ & & $762(93.5)$ & $53(6.5)$ & \\
\hline Other & $73(1.2)$ & $67(93.1)$ & $5(6.9)$ & & $63(87.5)$ & $9(12.5)$ & \\
\hline OHCA & $1817(8.1)$ & $1351(74.4)$ & $466(25.6)$ & & $938(51.6)$ & $879(48.4)$ & \\
\hline Neurological & $5523(24.6)$ & $4921(89.2)$ & $594(10.8)$ & & $4174(75.7)$ & $1341(24.3)$ & \\
\hline Intoxication & $2745(12.2)$ & $2726(99.5)$ & $15(0.5)$ & & $2690(98.1)$ & $51(1.9)$ & \\
\hline Other & $6168(27.5)$ & $5818(94.5)$ & $337(5.5)$ & & $5375(87.3)$ & $780(12.7)$ & \\
\hline
\end{tabular}

Note: OHCA, out-of-hospitalcardiac arrest

'Mann-Whitney U-test

* Chi-square

This article is protected by copyright. All rights reserved 
\# Two-sample t-test

This article is protected by copyright. All rights reserved 


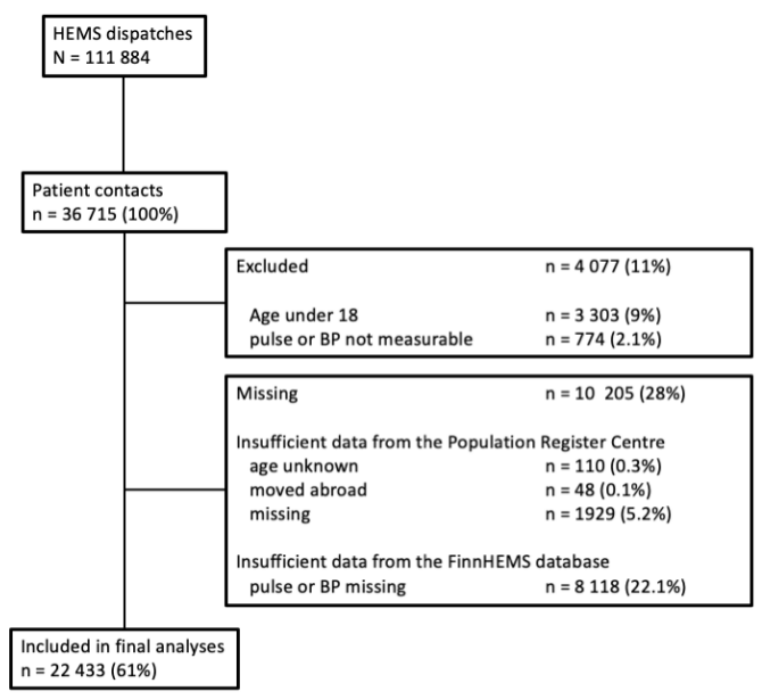

aas_13765_f1.tiff

This article is protected by copyright. All rights reserved 

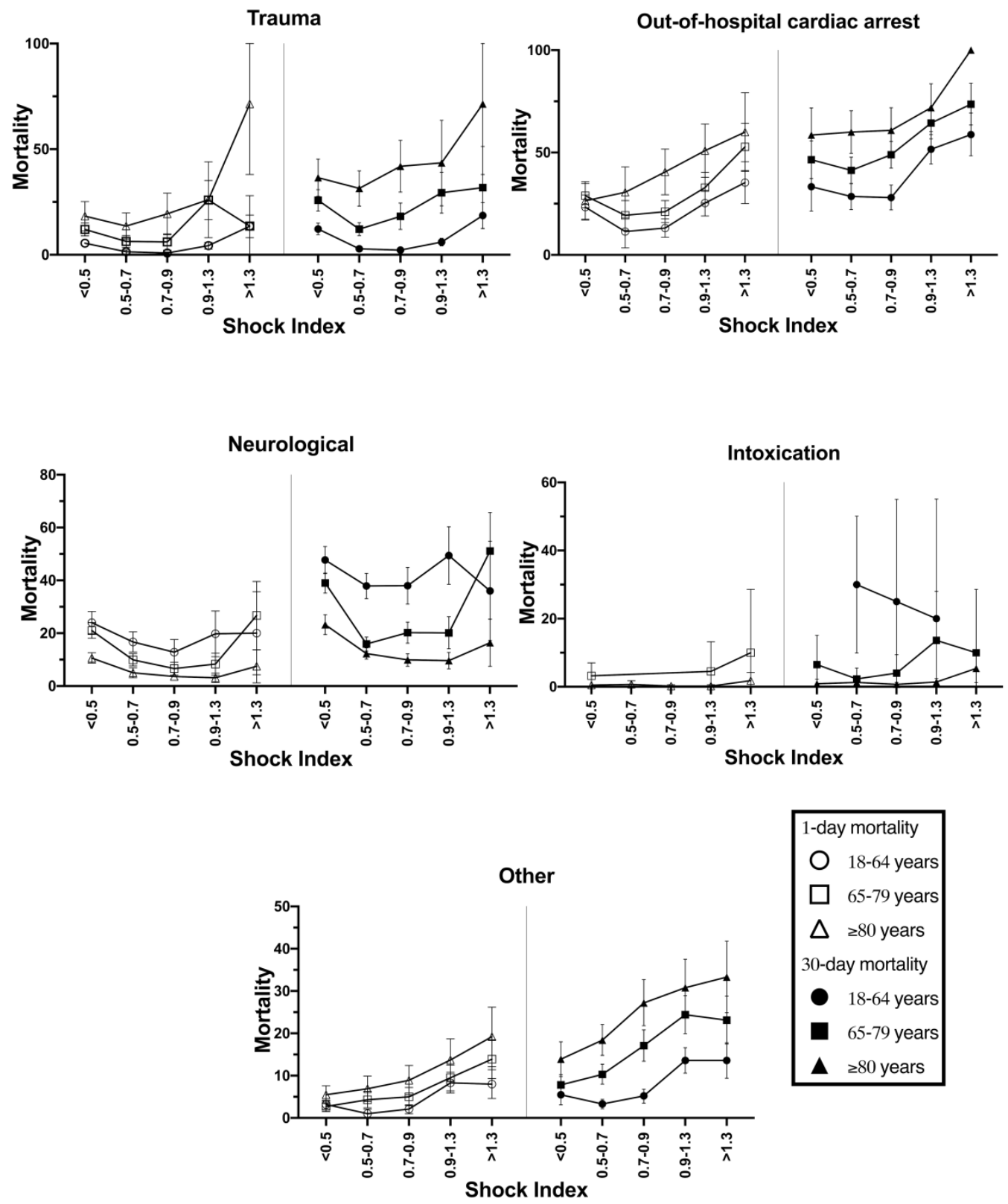

\begin{tabular}{|cc|}
\hline 1-day mortality \\
$\bigcirc$ & $18-64$ years \\
$\square$ & $65-79$ years \\
$\Delta$ & $\geq 80$ years \\
30-day mortality \\
$\boldsymbol{D}$ & $18-64$ years \\
$\mathbf{D}$ & $65-79$ years \\
$\boldsymbol{\Delta}$ & $\geq 80$ years \\
\hline
\end{tabular}

aas_13765_f2.tiff 

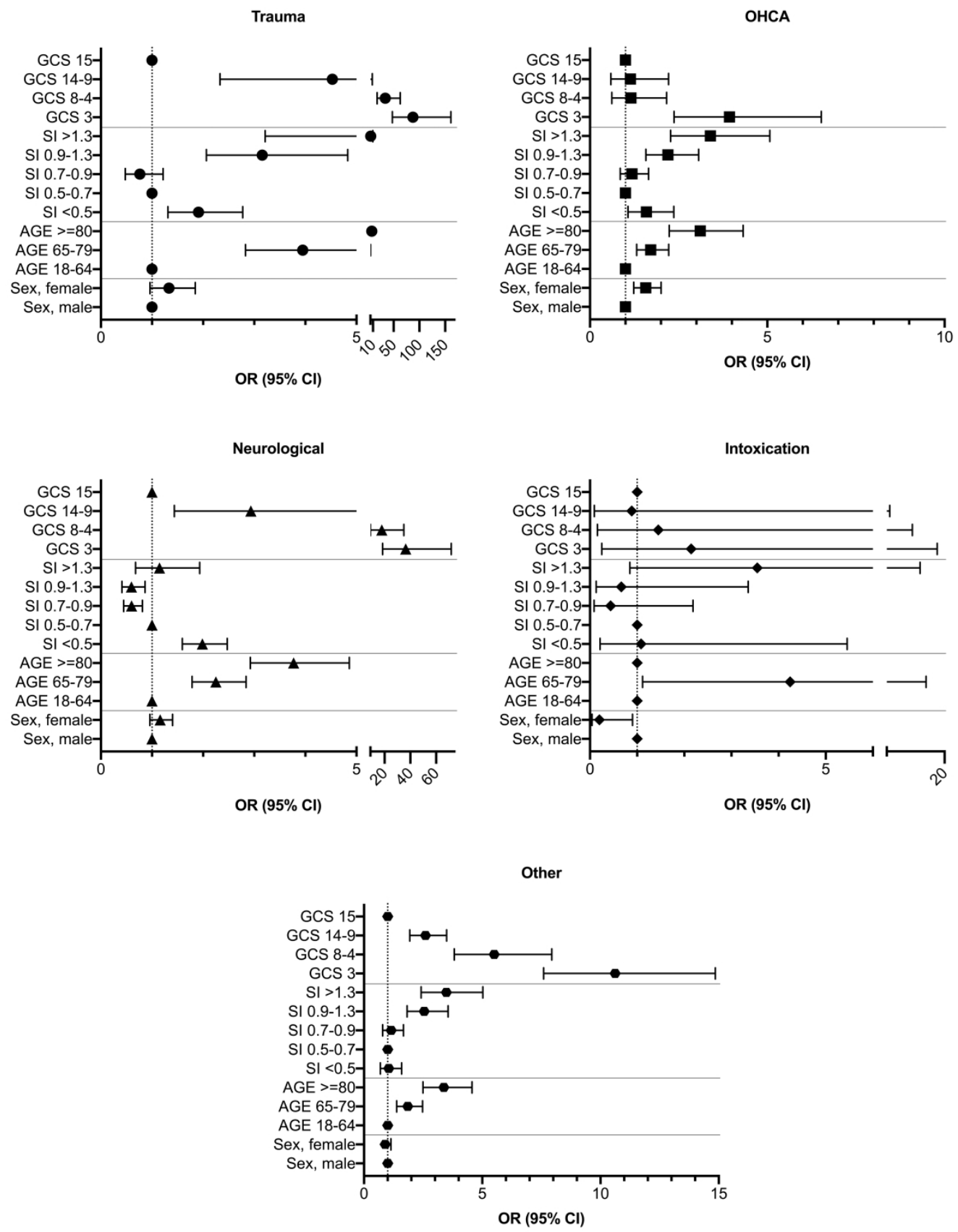

aas_13765_f3.jpg

This article is protected by copyright. All rights reserved 